\title{
Normal Doğumda ve Sezaryen Doğumda Anne Memnuniyetinin Belirlenmesi*
}

\section{Determination of Maternal Satisfaction at Normal and Cesarean Birth}

\author{
Şadiye ÖZCAN**, Ergül ASLAN***
}

İletişim/Correspondence: Şadiye ÖZCAN Adres/Adress: Erzincan Asker Hastanesi Merkez/ERZINCAN

Tel:04462234102-1621E-mail: sadiyeozcan24@gmail.com

\begin{abstract}
$\ddot{O} Z$
Amaç: Hastaneden taburcu olmadan önce, normal ve sezaryen doğum yapan lohusaların doğumdan memnuniyet düzeylerinin belirlenmesidir.

Yöntem: Çalışma Van Bölge Eğitim Araştırma Hastanesi’ne bă̆lı bulunan Kadın Hastalıklarl ve Doğum Hastanesi’nde Aralık 2012-Nisan 2013 tarihleri arasında yapıldı. Tanımlayıcı kesitsel türde olan çalışmanın evrenini araştırma kriterlerine uyan ve çalışmayı kabul eden tüm lohusalar oluşturdu. Örneklemine normal doğum yapan 300 ve sezaryen doğum yapan 300 olmak üzere toplam 600 lohusa alındı. Verilerin toplanmasında, kadınların demografik özellikleri, gebelik ve doğum ile ilgili tanitıcı özelliklere ait soruların yer aldı̆̆ı bir tanıtım formu, Normal Doğum ve Sezaryen Doğumda Anne Memnuniyetini Değerlendirme Ölçekleri kullanıldı. Kadınların bilgilendirilmiş onamları alınarak taburcu olmadan önce normal doğum sonrası en erken 18 saat ile en geç 24 saat sonra; sezaryen doğumda ise en erken 24 saat ile en geç 72 saatte yukarıda belirtilen anketler uygulandi.

Bulgular: Normal doğum yapan lohusaların ölçekte belirlenen kesme noktası değerine göre \%100'ünün; sezaryen doğum yapan lohusaların ise ölçekte belirlenen kesme noktası değerine göre \%95'inin doğum eyleminde verilen bakım ve hizmetlerden memnun olmadl$\breve{g}$ belirlendi. Normal doğum yapan lohusaların sezaryen doğum yapan lohusalara göre doğum sonu bebekle tanışma ve (p: ,000) postpartum dönemde aldıkları bakımdan ( $p$ : ,000) memnuniyetlerinin anlamlı olarak daha yüksek olduğu belirlendi. Sezaryen doğum yapan lohusaların ise normal doğum yapan lohusalara göre kararlara katılım ve bilgilendirmeden (p: ,000) ve hastane olanaklarından (p: ,000) memnuniyetlerinin anlamlı olarak daha yüksek olduğu bulundu.
\end{abstract}

Sonuç: Normal doğumda ve sezaryen doğumda anne memnuniyeti genel olarak düşük bulundu. Sezaryen oranlarının yüksek olduğu ülkemizde özellikle normal doğum yapan annelerin memnuniyetlerinin artırllması gerekmektedir.

Anahtar Kelimeler: Doğum, postpartum bakım, lohusa, hasta memnuniyeti.

\section{ABSTRACT}

Aim: The aim of this study was to determine maternal satisfaction at normal and cesarean birth before their discharge from the hospital. Method: Study was conducted in between December 2012-April 2013 at the Obstetrics and Gynecology Department of the Van Region and Research Hospital. Descriptive cross-sectional study was used. The sample included 300 normal birth and 300 cesarean, for a total of 600 healthy postpartum women. To gather the information, a brochure that contained demographics of women and questions on information regarding pregnancy and birth was used. In addition, The Scale for Measuring Maternal Satisfaction at Normal and Cesarean Birth was also used to gather the information. After giving informed consent, the scale was performed in between 18 to 24 hours for normal birth, between 24 to 72 hours for a cesarean birth before women's discharge.

Results: The results showed using the cut-off point of the scale, that 100\% of normal birth and 95\% of cesarean birth postpartum were not satisfied with care and services of giving birth. Mothers who had normal birth were found significantly higher satisfaction according to cesarean birth that meet the baby (p: ,000). and postpartum care (p: ,000). Mothers who had cesarean birth were found significantly higher satisfaction according to normal birth that participation and decision making and information ( $p$ : ,000) and hospital facilities ( $p$ : ,000).

Conclusion: The results of the study showed that the satisfactions of mothers were generally low for normal and cesarean births. The satisfaction of mother's that give normal births should be increased where Turkey has high cesarean birth rates.

Key Words: Birth, postpartum care, mother, patient satisfaction.

*İstanbul Üniversitesi Sağllk Bilimleri Enstitüsü Yüksek Lisans Tezi 2013, **Uzm. Hem. Erzincan Asker Hastanesi, ***Doç.Dr. İstanbul Üniversitesi Florence Nightingale Hemşirelik Fakültesi

Yazının gönderilme tarihi: 09.05.2014

Yazının basım için kabul tarihi: 25.12.2014 


\section{GİRIŞ}

Hasta memnuniyeti; hizmetin sunumunu, hasta ile hizmeti verenlerin etkileşimini, hizmetin varlığını, sürekliliğini, hizmeti verenlerin yeterliliği ve iletişim özelliklerini içeren çok boyutlu bir kavramdır (Avis, Bond ve Arthur 1995; Larsson, Larsson ve Starrin 1999; Y11maz 2000). Bu nedenle hasta memnuniyetinin temelini hasta beklentilerinin karşılanması, hastayı bilgilendirme ve iletişim oluşturmaktadır. Toplumlarda eğitim düzeyinin artmasıyla daha bilgili ve verilen bakımı/hizmeti eleştiren bireyler ortaya çıkmaya başlamıştır. Günümüzde hastalar kendi sağlık bakımına katılmak, karar verme sürecinde kendi durumlarının ne olduğunu öğrenmek ve tanılarını anlamak istemektedirler (Merkouris, Ifantopoulos, Lanara ve Lemonidou 1999). Hasta memnuniyetinin değerlendirilmesi, sağlık hizmet kalitesinin değerlendirilmesi ve sağlık alanındaki eksikliklerin belirlenmesi ve bu eksikliklerin giderilmesi için yol gösterici olabilmektedir. $\mathrm{Bu}$ nedenle hasta memnuniyeti; sağlik hizmetlerinin bir sonucu olarak kabul edilirken hemşirelik hizmetlerinin değerlendirilmesi ve kalitesinin belirlenmesinde de çok önemli geri bildirim sağlamaktadır (İçyeroğlu ve Karabulutlu 2011).

Hasta memnuniyeti ile ilgili çalışmalar ülkemizde de çeşitli sağlık kurumlarında sağlık hizmetlerinin iyileştirilmesine yönelik olarak giderek artmaktadır. Yapılan çalışmalarda hemşirelik bakımına ilişkin hasta memnuniyeti ile hastane hizmetlerinden memnuniyet arasında pozitif yönde bir ilişki olduğu belirlenmiştir. Hastaların hastane bakımından memnuniyetini etkileyen en önemli etkenin hemşirelik bakımından memnuniyetleri olduğu bildirilmektedir (İçyeroğlu ve Karabulutlu 2011). Pınar ve Pınar (2009)'ın çalışmalarında, doğum eylemindeki kadınların \%42,5'inin ebe/hemşirelere güven duyduklar1 ve \%45,2'sinin sorunlarını paylaşabildikleri belirtilmiştir. Ayrıca bu çalışmaya katılan kadınların ebe/ hemşirelerden beklentilerinin daha çok "azarlanmamak" $(\% 34,5)$ ve "güler yüzlü olmak" $(\% 13,8)$ olduğu da rapor edilmiştir. Diğer bir çalışmada da ise kadınların en fazla $(\% 41,6)$ cesaretlendirilmeye ihtiyaç duydukları ifade edilmiştir (Karaçam ve Akyüz 2011; P1nar ve P1nar 2009).

Doğum eyleminde memnuniyetin önemini ve düzeyini belirlemek için yapılan bir çalışmada; normal doğum yapanların \%65,6's1 doğum süresini tahmin ettiklerinden daha uzun, \%16,4'ü tahmin ettikleri sürede olduğunu belirtmiştir. Normal doğum yapanların $\% 80,5$ 'i ve sezaryen doğum yapanların $\% 40,6$ 's1 doğum olayının tahmin ettiklerinden daha ağrılı olduğunu söylemiştir. Normal doğum yapanların \%88,3'ü ve sezaryen ile doğum yapanların \%76,6'sı doğum şeklinden memnun olduğunu belirtmiştir (Yanıkkerem, Uçum, Kitapçığlu ve Karadeniz 2010).

Bu çalışmada hastaneden taburcu olmadan önce, normal ve sezaryen doğum yapan lohusaların doğumdan memnuniyet düzeylerinin belirlenmesi amaçlanmıştır.

\section{YÖNTEM}

Tanımlayıcı kesitsel nitelikteki bu çalışma, T.C. Sağlık Bakanlığı Van Bölge Eğitim Araştırma Hastanesi’ne bağlı Kadın Hastalıkları ve Doğum Hastanesi'nde Aralık 2012-Nisan 2013 tarihleri arasında yürütüldü.

Çalışmanın evrenini belirtilen tarihler arasında doğum yapan, araştırma kriterlerine uyan ve çalışmayı kabul eden tüm lohusalar oluşturdu. Araştırmamız tanımlayıcı kesitsel türde olup, araştırmanın örneklemine Van Bölge Eğitim Araştırma Hastanesi Kadın Hastalıklar1 ve Doğum Hastanesi'nde yatan, 18-45 yaş arasında, miyadında doğum yapmış (36 hafta ve üzeri), sağlıklı fetüse sahip, kronik hastalığı olmayan, gebelik ve doğumla ilgili herhangi bir komplikasyon yaşamamış olup, normal doğum yapan 300 ; sezaryen doğum yapan 300 olmak üzere toplam 600 lohusa yer aldı. Örneklem büyüklüğü evreni belli olan örneklem seçimi formülü ile hesaplanarak \%95 güven aralığında toplamda en az 372 olarak belirlendi.

Veriler gerekli kurum izinleri ve etik kurul onayı alındıktan sonra klinikte uygun ortam sağlanarak araştırmacı tarafindan yüz yüze görüşme yöntemiyle, normal 
doğum sonrası en erken 18 saat ile en geç 24 saat sonra; sezaryen doğumda ise en erken 24 saat ile en geç 72 saatte topland.

Veri toplama araçları olarak çok sorulu anket formu, Güngör İ. tarafından 2009'da geçerliği ve güvenirliği yapılan 'Doğumda Anne Memnuniyetini Değerlendirme Ölçeği (Normal Doğum)' ve 'Doğumda Anne Memnuniyetini Değerlendirme Ölçeği (Sezaryen Doğum)' uygulandi.

Anneler ve eşlerinin tanıtıcı özelliklerinin sorguland1ğ1 çok sorulu anket formu beş bölümden oluşmaktadır. Bu bölümlerde; demografik özellikler, doğuma hazurlık ile ilgili özellikler, obstetrik özellikler, doğum ve doğum yaptı̆̆ 1 yer ile ilgili özellikler ve doğumda uygulanan işlemler ile ilgili sorular bulunmaktadır. Normal Doğumda Anne Memnuniyetini Değerlendirme Ölçeği 43 madde ve 10 alt boyuttan oluşan 5'li likert tipi bir ölçektir. Alt boyutlar; sağlık ekibini alg1layışı, doğum eyleminde hemşirelik bakımı, rahatlatma, kararlara katılım ve bilgilendirme, bebekle tanışma, postpartum bakım, hastane odas1, hastane olanakları, mahremiyete saygı, beklentilerin karşılanmasıdır. On üç madde ters puanlıdır. Ölçek puanının hesaplanması için öncelikle ters puanlı maddeler çevrilir. Madde puanlarının ters çevrilmesinde "1-Katılmıyorum, 2-Kısmen kat1lıyorum, 3-Kararsızım, 4-Katıliyorum ve 5-Kesinlikle kat1liyorum" yerine "5-Katılm1yorum, 4-K1smen kat1liyorum, 3-Kararsızım, 2-Kat1l1yorum ve 1-Kesinlikle katılıyorum" şeklinde puanlanır. Ters puanlı maddeler çevrildikten sonra ölçekteki bütün maddelerin puanının toplamı "toplam ölçek puanını" verir. Her alt boyutu oluşturan maddelerin toplamı ise "toplam alt boyut puanı" olarak kullanılabilir. Toplam ham puan 43-215 arasında değişmektedir. Ö1çekten alınan toplam puan arttıkça annelerin normal doğumda hastanede aldıkları bakımdan memnuniyet düzeyleri artmaktadır. Normal Doğumda Anne Memnuniyetini Değerlendirme Ölçeği için hesaplanan kesme noktası puanı 150,5 olarak belirlenmiştir $(\geq 150,5$ memnuniyet düzeyi yüksek, $<150,5$ memnuniyet düzeyi düşük) (Güngör ve Beji 2012).
Sezaryen Doğumda Anne Memnuniyetini Değerlendirme Ölçeği 42 madde ve 10 alt boyuttan oluşan 5'li likert tipi bir ölçektir. Alt boyutlar; sağlık ekibini alg1layışı, sezaryene hazırlık, rahatlatma, kararlara katılım ve bilgilendirme, bebekle tanışma, postpartum bakım, hastane odası, hastane olanakları, mahremiyete sayg1, beklentilerin karşılanmasıdır. On iki madde ters puan11dır. Ters puanlı maddeler çevrildikten sonra ölçekteki bütün maddelerin puanının toplamı ile "toplam ölçek puanını" ve her alt boyutu oluşturan maddelerin toplamı ile "toplam alt boyut puanı" elde edilir. Toplam ham puan 42-210 arasında değişmektedir. Ölçekten alınan toplam puan arttıkça annelerin sezaryen doğumda hastanede aldıkları bakımdan memnuniyet düzeyleri artmaktadır. Sezaryen Doğumda Anne Memnuniyetini Değerlendirme Ölçeği için hesaplanan kesme noktası puanı 146,5 olarak belirlenmiştir ( $\geq 146,5$ memnuniyet düzeyi yüksek, $<146,5$ memnuniyet düzeyi düşük) (Güngör ve Beji 2012).

Lohusaların genel olarak kullandıkları dilin fark1 olmasından dolayı iletişim problemleri yaşanması, sosyo-demografik düzeylerinin düşük olmasından dolayı anket sorularını anlamakta zorlanma ve fiziksel şartların görüşmeye uygun olmaması araştırmanın s1nırlılıklarıdır.

Verilerin analizinde SPSS (Statistical Package for the Social Sciences) 16.0 programında yüzdelik, ortalama, standart sapma, Mann-Whitney U testi kullanıldı. Anlamlılık düzeyi $\mathrm{p}<0,05$ olarak kabul edildi.

\section{BULGULAR}

Normal doğum yapan lohusaların yaş ortalaması $26,42 \pm 5,74$ olup, $\% 18,3$ 'ü 20 yaş altında ve $\% 55,3$ 'ü 21-30 yaş grubundadır. Normal doğum yapan lohusaların ilk evlenme yaşı ortalama $17,41 \pm 1,31$, eğitim düzeyi \%71'inde okuryazardır. Kadınların \%99,3'ü ev hanım1, \%85,4'ünün kendi ifadesine göre ekonomik durumu orta düzeyde ve \%81,3'ünün sosyal güvencesi SGK'dır.

Normal doğum yapan hasta grubunda ölçeğe ilişkin alt boyut ve toplam puanlar Tablo 1'de verilmiştir. 
Tablo 1. Normal Doğum Yapan Lohusaların "Normal Doğumda Anne Memnuniyetini Değerlendirme Ölçeği” Puanları (n=300)

\begin{tabular}{|l|c|c|c|c|}
\hline Alt boyutlar & Ort. & SS. & Min. & Maks. \\
\hline $\begin{array}{l}\text { Sağlık ekibini } \\
\text { algılayış1 }\end{array}$ & 14,29 & 3,63 & 4,00 & 16,00 \\
\hline Hemşirelik bakımı & 7,10 & 1,94 & 2,00 & 9,00 \\
\hline Rahatlama & 8,57 & 1,89 & 5,00 & 20,00 \\
\hline $\begin{array}{l}\text { Kararlara katılım ve } \\
\text { bilgilendirme }\end{array}$ & 12,87 & 4,05 & 8,00 & 29,00 \\
\hline Bebekle tanışma & 6,75 & 1,56 & 3,00 & 13,00 \\
\hline Postpartum bakım & 18,18 & 4,67 & 6,00 & 25,00 \\
\hline Hastane odas1 & 10,30 & 3,97 & 4,00 & 16,00 \\
\hline Hastane olanakları & 6,26 & 2,37 & 3,00 & 12,00 \\
\hline Mahremiyete sayg1 & 15,99 & 2,67 & 8,00 & 19,00 \\
\hline $\begin{array}{l}\text { Beklentilerin } \\
\text { karşılanması }\end{array}$ & 14,35 & 2,42 & 7,00 & 22,00 \\
\hline Toplam Puan & $\mathbf{1 1 4 , 7 0}$ & $\mathbf{1 2 , 2 1}$ & $\mathbf{6 1 , 0 0}$ & $\mathbf{1 4 6 , 0 0}$ \\
\hline
\end{tabular}

Normal doğum yapan annelerin memnuniyet ortalama puanı 114,70 $\pm 12,21$ olarak bulundu. Bu değerlerler daha önce memnuniyet için belirlenen 150,5 kesme noktası değerinin altında olduğundan memnuniyet düzeyi \%100 oranında düşük bulundu.

Sezaryen doğum yapan lohusaların yaş ortalaması $25,57 \pm 4,52$ olup, lohusaların $\% 60,3$ 'ü 21-25 yaş grubundadır. Sezaryen doğum yapan lohusaların ilk evlenme

Tablo 2. Sezaryen Doğum Yapan Lohusaların "Sezaryen Doğumda Anne Memnuniyetini Değerlendirme Ölçeği” Puanları (n=300)

\begin{tabular}{|l|c|c|c|c|}
\hline Alt boyutlar & Ort. & SS. & Min. & Maks. \\
\hline $\begin{array}{l}\text { Sağllk ekibini } \\
\text { algılayış1 }\end{array}$ & 17,55 & 3,66 & 5,00 & 23,00 \\
\hline Sezaryene hazırlık & 6,05 & 2,07 & 2,00 & 9,00 \\
\hline Rahatlatma & 7,62 & 2,35 & 4,00 & 15,00 \\
\hline $\begin{array}{l}\text { Kararlara katılım ve } \\
\text { bilgilendirme }\end{array}$ & 22,02 & 4,97 & 8,00 & 32,00 \\
\hline Bebekle tanışma & 6,23 & 2,90 & 3,00 & 15,00 \\
\hline Postpartum bakım & 17,30 & 3,07 & 7,00 & 25,00 \\
\hline Hastane odas1 & 9,11 & 2,82 & 3,00 & 12,00 \\
\hline Hastane olanaklar1 & 8,72 & 1,82 & 3,00 & 13,00 \\
\hline Mahremiyete sayg1 & 15,59 & 2,72 & 7,00 & 20,00 \\
\hline $\begin{array}{l}\text { Beklentilerin } \\
\text { karşılanmas1 }\end{array}$ & 14,78 & 2,82 & 7,00 & 24,00 \\
\hline Toplam puan & $\mathbf{1 2 4 , 9 9}$ & $\mathbf{1 3 , 6 8}$ & $\mathbf{7 5 , 0 0}$ & $\mathbf{1 6 7 , 0 0}$ \\
\hline
\end{tabular}

yaş1 ortalama $17,44 \pm 1,21$, eğitim düzeyi $\% 41$ 'inde okuryazar, \%48'inde ilköğretim mezunu; \%98'i ev hanımı, \%87'sinin kendi ifadesine göre ekonomik durumu orta düzeyde ve \%82'sinin sosyal güvencesi SGK'dır.

Sezaryen doğum yapan hasta grubunda ölçeğe ilişkin alt boyut ve toplam puanlar Tablo 2 'de verilmiştir.

Sezaryen doğum yapan annelerin memnuniyet ortalama puanı 124,99 $\pm 13,68$ olarak bulundu. Bu değerlerler daha önce memnuniyet için belirlenen 146,5 kesme noktası değerinin altında olduğundan memnuniyet düzeyi $\% 95$ oranında düşük bulundu.

Normal doğumda yapılan rutin uygulamaların anne memnuniyetine etki düzeyi Tablo 3'de verilmiştir.

Normal doğumda lavman yapılan lohusaların sağlik ekibinden (p: ,020) ve mahremiyete gösterilen sayg1dan (p: ,003) memnuniyetlerinin anlamlı olarak daha yüksek olduğu; kararlara katılım ve bilgilendirmeden (p: ,029) memnuniyetlerinin anlamlı olarak daha düşük olduğu belirlendi.

Oksitosin indüksiyonu uygulanan lohusalarda hastane olanaklarından memnuniyetin anlamlı derecede yüksek olduğu görüldü (p: ,005).

Epizyotomi yapılmayan lohusaların kararlara katılım ve bilgilendirmeden (p: ,029), hastane odasindan (p: ,017), beklentilerin karşılanmasından (p: ,008) memnuniyetlerinin ve ölçek toplam puanının epizyotomi yapılmayanlarda anlamlı olarak daha yüksek olduğu bulundu (p: ,005).

Doğum sırasında fundal basınç uygulanmayan lohusaların sağlık ekibini algılayışı (p: ,034) ve doğum eyleminde hemşirelik bakımından (p: ,008) memnuniyetlerinin anlamlı olarak daha yüksek olduğu belirlendi.

Lohusaların \%94,4'üne ağrı kontrolü için hiçbir girişim yapılmadı. Farmakolojik yöntemlerle ağrı kontrolü sağlanan lohusaların ise kararlara katılım ve bilgilendirilmeden memnuniyetlerinin (p: ,039) anlamlı olarak yüksek olduğu belirlendi.

Her iki doğum şekline özgü memnuniyet ölçeklerinin "sezaryene hazırlık" dışında diğer alt boyutlarının puanlaması ortak olup, karşılaştırması Tablo 4'de verilmiştir. 
Normal Doğumda ve Sezaryen Doğumda Anne Memnuniyetinin Belirlenmesi

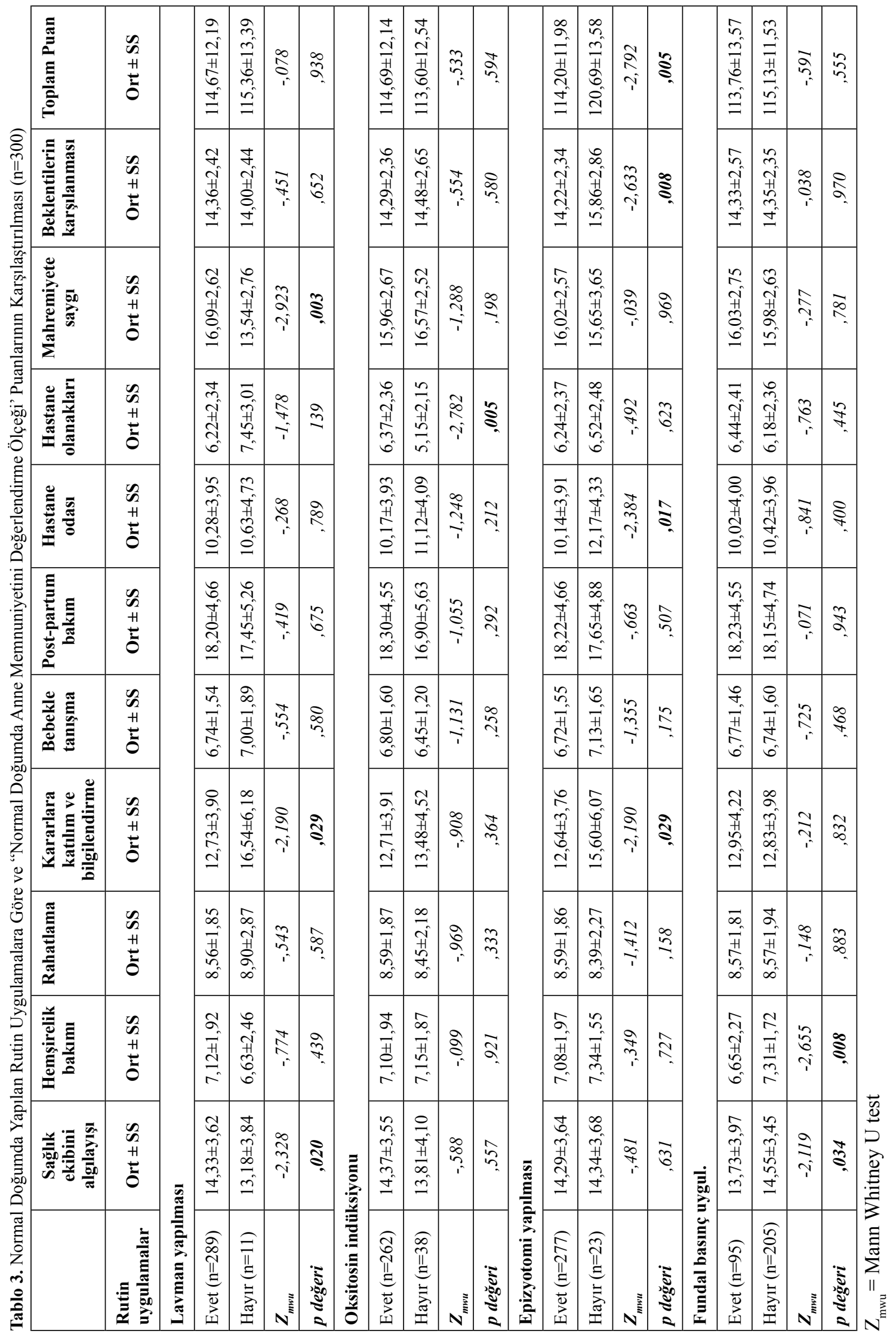




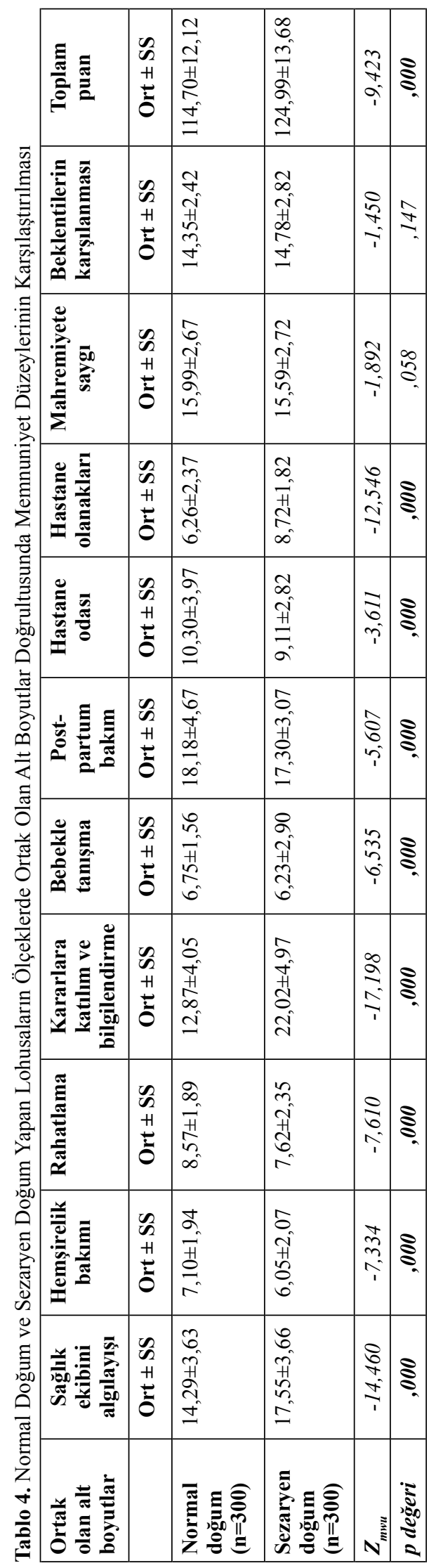

Normal doğum yapan lohusaların sezaryen doğum yapan lohusalara göre hemşirelik bakımı (p: ,000); rahatlama (p: ,000); bebekle tanışma (p: ,000); postpartum bakım (p: ,000); ve hastane odası (p: ,000) memnuniyetlerinin anlamlı olarak daha yüksek olduğu belirlendi.

Sezaryen doğum yapan lohusaların ise normal doğum yapan lohusalara göre sağlık ekibini algılayışı (p: ,000); kararlara katılım ve bilgilendirme (p: ,000) ve hastane olanaklarından (p: ,000) memnuniyetlerinin anlamlı olarak daha yüksek olduğu bulundu.

Toplam ölçek puanlarında da sezaryen doğumdan memnuniyetin normal doğuma göre daha fazla olduğu görüldü (p: ,000).

\section{TARTIŞMA}

Kadınların yaşamında çok önemli bir deneyim olarak görülen doğum ve kadının bu dönemdeki memnuniyeti, kadının kendi sağlı̆̆g, bebeğinin sağlı̆̆ 1 ve olumlu aile ilişkileri açısından son derece önemlidir. Olumsuz bir doğum deneyimi kadında postpartum depresyon, sonraki gebeliği istememeye bağlı küretaj, sezaryen isteği, cinsel işlev bozukluğu, anne-bebek bağlanmasında yetersizlik, emzirme sorunları ve bebeği ihmal gibi durumlara neden olabilmektedir (Britton 2006; Goodman, Mackey ve Tavakoli 2004; Harvey, Rach, Stainton, Jarrell ve Brant 2002; Waldenström, Hildingsson, Rubertsson ve Radestad 2004).

Chen ve ark. (2001) yaptığı çalışmasında, kadınların \%98'i doğum eyleminde hemşirelerin ağrılarını rahatlatarak ve kendi kendilerini güvende hissettirerek, kendi kendilerine kontrol kazanmalarını kolaylaştırdığını bildirmişlerdir. Kadınların \%86'sı hemşirelerin bilgi verdiklerini ve tavsiyeler sunduklarını bildirmişlerdir. Bu bilginin de nefes alıp vermeyi öğretmesi, yürüme ve pozisyonları ayrıca doğumda 1 kınma, bebeği itme tekniklerini içerdiğini bildirmişlerdir. Ayrıca hemşireler doğum süreci ve prosedürleri, annenin ve bebeğin iyilik halleri hakkında da bilgi vermişlerdir. $\mathrm{Bu}$ bilgilerin kadının rahatlamasına korkusunun azalmasına ve kadının doğum eylemine uyum sağlamasına 
yardımcı olduğu belirtilmiştir. Doğum eylemine uyum sağlamış ve rahatlamış kadının doğumdaki deneyimini olumlu değerlendirme olasılığı da artmaktadır. Williams bilgilendirilen hastaların sağlık personeline olan güvenlerinin ve memnuniyet düzeylerinin arttığ1nı saptamıştır (Eker ve Yurdakul 2008). Çalışmamızda normal doğum yapan lohusaların kararlara katılım ve bilgilendirme alt boyutundan ald1kları puan ortalamas1 sonucunda memnuniyet oran $\% 30$ iken; sezaryen doğum yapanların ise yaklaşık \%50 civarındadır. Çalışmamızdaki ortalama puanlardan normal doğum eyleminde lohusaların kararlara katılımı için onayının alınmadığı ve doğum süreci ile ilgili olarak yeterince bilgilendirilmediği sonucuna varılabilir. Bunun da lohusaların memnuniyetlerini etkileyebileceği düşünülmektedir. Ayrıca sezaryen doğum yapan lohusaların doğum süreci ile ilgili olarak daha çok bilgilendirildikleri ve bunun da memnuniyetlerini normal doğuma göre daha çok artırdığı düşünülmektedir.

Çoğu kadın anne ve bebek sağlığı için ciddi bir sorun oluşmadığı sürece doğumu hızlandırmak veya kolaylaştırmak amacıyla yapılan oksitosin indüksiyonu uygulaması, lavman, amniotomi, vakum, fundal basınç vb. tıbbi girişimlerin yapılmasını istemez. Bu nedenle doğuma yapılan müdahalelerin, doğum deneyiminden duyulan memnuniyeti de etkilediği düşünülmektedir. Ancak ülkemizde özellikle eylemi hızlandırmak amacryla kullanılan rutin işlemlerin gereğinden fazla uygulandığ 1 bildirilmektedir (Güngör ve Beji 2012). Çalişmamızda normal doğum yapanlarda lavman, oksitosin indüksiyonu ve epizyotomi uygulaması $\% 90$ civarında uygulanmaktadır. Bunun da memnuniyeti etkilediği düşünülmektedir.

Ezeanochie ve ark. (2013) doğumda kadınların endişeleri, deneyimleri ve memnuniyetlerini araştırmak için Nijerya'da yaptığı çalışmada genel olarak kadınların \%71,4'ü doğumda oksitosin indüksiyonu uygulamasından memnun olduğunu, \%28,6's1 ise memnun olmadığını belirtmiştir. Nispeten, daha yüksek yaş ortalaması ve daha kısa indüksiyon-doğum aralığı doğumda anne memnuniyeti ile önemli derecede ilişkili bulunmuştur. Doğumda memnuniyetsizliğin ortak ne- deni olarak \%13,4 "acil sezaryen”, \%8,7 "ağrılı doğum” ve \%2,4 "doğum eyleminin uzaması"dır. Yine aynı çalışmada doğumda oksitosin indüksiyonu uygulanan önemli sayıda gebenin memnuniyet düzeylerinin daha düşük olduğu belirtilmiştir.

Mohammad ve ark. (2014) Ürdün'de yaptıkları anne memnuniyetini değerlendiren çalışmada lohusaların \%75.6'sının doğumda aldıkları bakımdan memnun olmadıkları bulunmuştur. Kadınların memnuniyetsizliği doğumlarına istemedikleri ve tanımadıkları kişilerin katılmasıyla, doğum eyleminin tahmin ettiklerinden daha ağrılı olmasıyla ve sağlık bakımı verenlerin doğum ağrısının yönetilmesinde yetersiz yardım etmesiyle ilişkili bulunmuştur. Araştırmamızda da nerdeyse hiçbir gebeye farmakolojik olarak ağrı kontrolü sağlanmamıştır.

\section{SONUÇ VE ÖNERILER}

Türkiye genelinde doğurganlık hızı en yüksek olan iller arasında altıncı sırada yer alan Van ilinde yapılan bu araştırma sonucunda, normal ve sezaryen doğumda anne memnuniyeti, doğum sürecinde uygulanan girişimlerin fazla olması, gebelerin doğum sürecinde yeterince desteklenememesi, hasta sayısının fazla olması ve hasta ile sağlık personeli arasındaki iletişimin zayıf olmasından dolayı düşük bulunmuştur.

Ülkemizde özellikle doğum korkusu ve doğumda travma yaşama endişesi ile artan sezaryen doğumların oranlarının azaltılması, en az tıbbi müdahalenin yapıldığı, kadının desteklendiği ve ağrısıyla nonfarmakolojik yöntemlerle başedebildiği doğumların artırılmas1 gerekir. Kadınların normal doğum yapmaya cesaretlendirilerek memnuniyetlerinin artırılması birey ve toplum sağlığı açısından oldukça önemlidir.

\section{KAYNAKLAR}

Avis, M., Bond, M., Arthur, A. (1995). Exploring patient satisfaction without patient services. J Nurs Manag., 3(2): 59-65.

Britton, J. R. (2006). Global satisfaction with perinatal hospital care: Stability and relationship to anxiety, depression, and stressful medical events. American Journal of Medical Quality, 21(3): 200-205. 
Chen, C. H., Wang, S. Y., Chang, M.Y. (2001). Women's perceptions of helpful and unhelpful nursing behaviors during labor: A study in Taiwan. Birth, 28(3): 180-185.

Eker, A., Yurdakul, M. (2008). Sezaryen sonrası verilen bakımın hasta memnuniyetine etkisi. Mersin Üniv. Sağlık Bilim Dergisi, 1(1): 26-35.

Ezeanochie, M. C., Olaqbuji, B., Ande, A. (2013). Women's concerns and satisfaction with induced labour at term in a Nigerian population. Niger Postgrad Med. J., 20(1): 1-4.

Goodman, P., Mackey, M. C., Tavakoli, A. S. (2004). Factors related to childbirth satisfaction. J. Adv. Nurs., 46(2): 212-219.

Güngör, İ., Beji, N. K. (2012). Development and psychometric testing of the scales for measuring maternal satisfaction in normal and caesarean birth. Midwifery, 28(3): 348-357.

Harvey, S., Rach, D., Stainton, M., Jarrell, J., Brant, R. (2002). Evaluation of satisfaction with midwifery care. Midwifery, 18(4): 260-267.

İçyeroğlu, G., Karabulutlu, E. (2011). Hastaların hemşirelik bak1mından memnuniyet düzeylerinin belirlenmesi. Firat Să̆lık Hizmetleri Dergisi, 6(7): 67-81.

Karaçam, Z., Akyüz, E. Ö. (2011). Doğum eyleminde verilen destekleyici bakım ve ebe/ hemşirenin rolü. İ.Ü.F.N. Hem. Derg., 19(1): 45-53.
Larsson, B. W., Larsson, G., Starrin, B. (1999). Patients' views on quality of care: A comparison of men and women. J Nurs Manag., 7(3): 133-139.

Merkouris, A., Ifantopoulos, J., Lanara, V., Lemonidou, C. (1999). Patient satisfaction: A key concept for evaluation and improving nursing services. Journal of Nursing Management, 7(1): 19-28.

Mohammad, K. I., Alafi, K. K., Mohammad, A. I., Gamble, J., Creedy, D. (2014). Jordanian women's dissatisfaction with childbirth care. International Nursing Review, 61(2): 278-284.

Pınar, G., Pınar, T. (2009). Yeni doğum yapmış kadınların empatik iletişim beklentilerinin ebe/hemşireler tarafından karşılanma durumu. Tıp Araştırmaları Dergisi, 7(3): 132-140.

Waldenström, U., Hildingsson, I., Rubertsson, C., Radestad, I. (2004). A negative birth experience: Prevalence and risk factors in a national sample. Birth, 31(1): 17-27.

Yanıkkerem Uçum, E., Kitapçıŏ̆lu, G., Karadeniz, G. (2010). Kadınların doğum yöntemlerine bakış açısı, deneyim ve memnuniyetleri. Firat Sağllk Hizmetleri Dergisi, 5(13): 107-123.

Yılmaz, M. (2000). Ameliyat öncesi öğretimin ameliyat sonrası komplikasyonlara ve hasta memnuniyetine etkisi. Yayınlanmamış Doktora Tezi, Hacettepe Üniversitesi Sağlık Bilimleri Enstitüsü, Ankara. 